\title{
Nomogram of Umbilical, Mean Cerebral and Uterine Arteries Resistive Index at $28-40$ Weeks of Gestation in Cameroonian Population: A Pilot Study
}

\section{Boniface MOIFO}

Faculté de Medécine et des Sciences biomédicales dlUniversité de Yaoundé1

Ulrich Gael TENE ( $\square$ ulrichtene@yahoo.fr)

Universite de Yaounde I Faculte de Medecine et des Sciences Biomedicales https://orcid.org/00000002-5949-3861

\section{Carine NJOMATCHOUA}

Universite de Yaounde I Faculte de Medecine et des Sciences Biomedicales

\section{Jean Roger MOULIOM TAPOUH}

Universite de Yaounde I Faculte de Medecine et des Sciences Biomedicales

\section{Pascal FOUMANE}

Universite de Yaounde I Faculte de Medecine et des Sciences Biomedicales

\section{Research article}

Keywords: Nomogram, Resistive index, singleton pregnancy, Cameroon, low risk pregnancy, fetal Doppler

Posted Date: September 14th, 2020

DOl: https://doi.org/10.21203/rs.3.rs-57352/v1

License: (1) This work is licensed under a Creative Commons Attribution 4.0 International License. Read Full License 


\section{Abstract}

\section{Background:}

Mother and fetal Doppler ultrasound during pregnancy is an established and safe tool for quantitative analysis of the utero-placental and the fetoplacental blood flow and seems to be affected by Ethnic hetérogenicity.

\section{Objective.}

To establish normative data for the resistive index of Uterine arteries, Umbilical artery and middle cerebral artery of Cameroonian pregnant women in the second half of pregnancy using multiples of the median and percentile reference range.

\section{Methods.}

We conducted a cross-sectional study on 93 low risk singleton gestation women aged above 18 years between 28 and 39 weeks of gestation in two hospitals in Cameroon during 7 months. We seek for resistive index (RI) of both left and right uterine arteries (LUt and RUt), Umbilical artery (UmA) and Middle cerebral artery (MCA). We also estimated the gestational age (GA), the mother age, the fetal weight (EFW) and the cerebro - placental ration (CPR).Pearson's correlation analysis of the relationship between these $\mathrm{RI}$ and selected maternal parameters was done. Regression modeling across gestational age was performed to obtain the reference values and normogram curve with values ranged at 5 and 95 th percentiles. $P<0.05$ was considered statistically significant.

\section{Results.}

The mean GA and EFW was $33.5+/-2.92$ weeks (médian of 34) and $2337.5+/-734$ g respectively. The means RI value of target vessels were $0.55+/-0.077 ; 0.76+/-0.071 ; 0.48+/-0.077$ and $0.46+/-0.087$ for UmA, McA, RUt and LUt with extremes values of des 0.38 to $0.77 ; 0.49$ to $0.87 ; 0.30$ to 0.70 and 0.29 to 0.69 respectively. Only UmA RI and CPR values had shown correlations with $G A(r=-0.338, p \leq 0.01$ and $r=0.314 ; p \leq 0.001)$ and EFW ( $r=-0.445, p \leq 0.001$ and $r=0.234 ; p=0.02)$. No difference between LUt and RUt RI values was found. The nomogram curve for UmA, McA, RUt and LUt value revealed a general low RI values of in our sample.

\section{Conclusions.}

Fetal Doppler should carefully interpreted according to general low RI values during low risk singleton pregnancy shown by this study. The generated 5and 95th percentiles RI values curves for each target vessel could be useful in that way.

\section{Trial registration:}


N*431/UY1/FMSB/VDRC/CSD du 24 mai 2017 by the Institutional Review Board at the faculty of Medicine and Biomedical Sciences of University of Yaoundé 1.

\section{Background}

The use of Doppler ultrasound in pregnancy is actually the most reliable, non-invasive and low cost method for exploration of hemodynamic changes in mother and fetus (1). Antepartum fetal surveillance with Doppler ultrasound has shown significant diagnostic efficacy for hemodynamic complications, such as intrauterine growth restriction (IUGR) and preeclampsia. This great interest of Doppler mode in pregnancy is not only due to be capable of studying materno - fetal blood circulation but meanly by the opportunity to provide novel indicators to evaluate the well-being of the fetus in utero (1).

Many vessels can be explored by the antenatal use of Doppler (such as umbilical artery, cerebral arteries, Arantius canal, fetal aorta, uterine arteries, etc.) with different meanings in term of feasibility and utility (2). For instance, umbilical arteries are the most explore vessel in pregnancy. Blood flow evaluation of umbilical arteries permits abnormal perfusion diagnosis (3). Focus clinical situations included intrauterine growth retardation, impaired amniotic fluid volume or active fetal movement, prematurity or suspected fetal death. Other vessels show similar utilities such as uterine arteries in preeclampsia (4-7) and Middle cerebral artery in situation of worse fetal prognostic due to hypoxia (8-11). Utero - placental blood fow is supply by uterine arteries and their analysis is useful in placentation abnormities by exploring the utero - placental resistance and abnormalities associated (12).

Many Doppler parameters can be used in obstetrics like end-diastolic velocity (EDV), peak systolic velocity (PSV), pulsatility index ( $\mathrm{PI})$, resistance index ( $\mathrm{RI})$, and systolic to diastolic ratio (S/D ratio) (5). It is the RI which is widely used in Obstetrical clinical routine in ours milieu. It reflects the measurement of flow resistances distal to to the point assessed unlike of PI that reflect resistance at the level assessed. Doppler waveforms and parameters help to predict and detect clinical situations linked to utero placental insufficiency and impaired fetus well-being by comparing with normal value contains in nomograms. The use of nomogram established by other countries particulary north developed countries $(3,13-17)$ may not be appropriate in sub saharan african populations who have different heteroginicty in ethnicity than in north people. In fact, there are some evidences that heterogenicity in the ethnicity influence both fetal and maternal blood flow, thus affects the fetal growth during pregnancy particularly during the last trimester (18). Our purpose in this study was to establish normative data for the resistive index of Uterine arteries, Umbilical artery and middle cerebral artery at the second half of pregnancy in a Sub Saharan country like the Cameroon.

\section{Methods}

This is a hospital-based cross sectional clinical study to obtain normal reference values of Umbilical, Mean cerebral and uterine resistive index in the second and thirdtrimester of pregnancy among healthy 
normotensive pregnant women at two Gyneacological and obstetrical Hospitals in Yaoundé and in Douala in Cameroonduring December 2016 and June 2017.

We evaluated once 93 women with normal singleton pregnancy with their gestation age between 28 to 39 +6 weeks. Fetal age was calculated based on the last menstrual period and cross checked by sonographic measurement of the biometrical parameters (Biparietal diameter, Cranial and abdominal circumferences, femoral length) using the Hadlock method (19).

Pregnant women with singleton gestation who had no demonstrable fetal abnormality were recruited if they satisfy other inclusion criteria of: appropriate GA, normal blood pressure (BP), tested negative for proteinuria, normal estimated fetal weight within 5thand 95th percentiles and had none of the following exclusion criteria such as history of diabetes, chronic hypertension, alcohol and drug abuse, uterine anomaly, fetal anomaly, use of medication for hypertension, corticosteroids use, sickle cell, or vascular disorders that may affect Doppler measurements

Of the 129 pregnant women during the studied period, we excluded those patients without regular prenatal surveillance and birth records. Patients were also excluded if they had any disease during the study or received a regimen of tocolytic and antihypertensive agents during pregnancy. Pregnancy outcome was confirmed by reviewing hospital medical records.

\section{Ultrasound examination}

All sonographic examination was performed with a MINDRAY DC-6/DC-7, de high definition equipped with a 2.5 - to $6 \mathrm{MHz}$ transducer. For beginning, each pregnant women benefit for a routine obstetrical US scan which help us to exclude multiple pregnancy, any placental, amniotic fluid or congenital abnormalities and permit us toobtain the estimated fetal weight by Hardlock formulae generated by the machine.Then we seek for RI of targeted arteries in this order:

First the umbilical arteries, color Doppler mode measures had been taken at the placental emergence of the cord after obtained waves separated from venous flux with an insonation angle inferior to $30^{\circ}$.

Second the mean cerebral arteries, a bi-dimensional axial scan of the fetal brain, including the thalami and cavitas septi pellucidi, was obtained. The circle of Willis and middle cerebral arteries were visualized using color flow mapping. Pulsed-wave Doppler velocimetry of the MCA closest to the transducer was obtained. The Doppler gate size of $4-5 \mathrm{~mm}$ was positioned close to the origin of the artery, near the internal carotid artery. The beam-blood vessel angle was kept near to $0^{\circ}$ but always less than $20^{\circ}$.

At last the uterine arteries, the patients were scanned in a semi-recumbent position with a slight lateral tilt. This minimizes the risk of developing supine hypotension syndrome due to inferior caval compression. The patient's abdomen was exposed fromthe xiphisternum to the groin hairline. The uterine artery was 
located by the transabdominal approach by placing the transducer longitudinally in the lower lateral quadrant of the abdomen with a slight medial angulation according to the method of Bhide et al (16). Color Doppler imaging was then used to identify the uterine artery as it is seen crossing the external iliac artery. The wall filter was kept at a low value $(50-60 \mathrm{~Hz})$ and the angle of insonation set below $20^{\circ}$. Then, pulsed wave Doppler with a gate size of $2 \mathrm{~mm}$ was placed over it at about $1 \mathrm{~cm}$ below the crossover point to generate the wave pattern. Both uterine arteries were insonated, the right before the left.

For all arteries, measurements were made on three consecutive uniform waveforms after recording six consecutive spectral waveforms of similar size and shape. We collected each generated RI by the machine with the formulae used (SD)/S. The wecalculed the Cerebro - placental ration by dividing each UmA RI value to McA RI value of the same fetus adjusted to two decimals.

\section{Statistical analysis}

Statistical analysis was performed using SPSS 14.0 (SPSS Inc., Chicago, IL, USA). Variables demonstrated as Mean \pm Standart Deviation (SD). A value of $P<0.05$ was considered statistically significant. Pearson correlation and Regression were used for evaluation of correlation between indices and gestational age. Reference ranges ( $90 \%$ range between 5th and 95th centiles) and the 95\% confidence interval were constructed for each parameter and displayed in graphic form. Linear, quadratic and cubic regression models were fitted to estimate the relationship between fetal Doppler variables and gestational age (in weeks). The best fitting model for each variable was selected.

\section{Results}

Data of the 93 eligible participants fulfilling the inclusion and exclusion criteria were analyzed. The mean maternal age was $29.6+/-5.03$ (range 18 to 51) years. Each GA week were represented. Mean GA was $33.5+/-2.92$ weeks similar to median (34 weeks). The mean EFW was $2337.5+/-734 \mathrm{~g}$. Both GA and EFW had a normal distribution. Maternal and fetal demographic data and percentiles of Doppler RI of target arteries of this study are shown in Table 1.

Table 1. Means, and standard deviations of demographic and quartiles Doppler Resistive index findings in study population 


\begin{tabular}{|llllllll|}
\hline & Mean & SD & \multicolumn{2}{l|}{ Percentiles } & & \\
& & & $10^{\mathrm{e}}$ & $25^{\mathrm{e}}$ & $50^{\mathrm{e}}$ & $75^{\mathrm{e}}$ & $90^{\mathrm{e}}$ \\
\hline Age (yr) & 29.6 & 5.03 & & & & & \\
\hline Estimated fetal weight (g) & 2337.5 & 734.7 & & & & & \\
\hline Gestational age (wk) & 33.5 & 2.92 & & & & & \\
\hline Resistive Index & & & & & & & \\
\hline \multicolumn{1}{|c|}{ Umbilical artery } & 0.55 & 0.077 & 0.46 & 0.51 & 0.56 & 0.60 & 0.67 \\
\hline Middle cerebral artery & 0.76 & 0.071 & 0.67 & 0.73 & 0.78 & 0.81 & 0.84 \\
\hline Cerebro - placental ratio & 1.39 & 0.212 & 1.14 & 1.26 & 1.39 & 1.52 & 1.65 \\
\hline Uterines arteries & & & & & & & \\
\hline Right & 0.48 & 0.077 & 0.39 & 0.41 & 0.46 & 0.53 & 0.55 \\
\hline Left & 0.46 & 0.087 & 0.35 & 0.41 & 0.48 & 0.53 & 0.57 \\
\hline
\end{tabular}

\section{Resistive index reference curves}

The reference curves of the resistive index (RI) of all the target arteries is characterized by a cubic pattern according to GA in week. Showing for UmA and McA RI values, a decrease from 0.61 to 0.48 and from 0.82 to 0.79 at $28-40$ weeks' gestation respectively with a peak RI at 34 weeks (0.59) and 32 weeks (0.79). Otherwise LUt and RUt RI shown an increase from 0.43 to 0.45 and from 0.45 to 0.61 without a real peak. The assume total of subject out of the 5th -95 th percentiles curves for each RI value of the targeted arteries was less than $4 \%$. Table 2, 3, 4, 5 shows 5 th, 50th, 95 th percentile values for Doppler waveform RI of Umbilical artery, Mean cerebral artery and both Left and right uterine arteries.

Table 2. 5th, 50th, 95th percentile values for Doppler waveform RI of Umbilical artery, 


\begin{tabular}{|c|c|c|c|c|c|c|c|c|}
\hline & & \multicolumn{7}{|c|}{ Doppler waveform RI of Umbilical artery } \\
\hline & & $\mathrm{n}$ & Mean & SD & 5thcentile & Median & 95thcentile & Maximum \\
\hline \multirow{12}{*}{$\begin{array}{l}A G \\
(w k)\end{array}$} & 28 & 6 & 0.61 & 0.07 & 0.55 & 0.58 & 0.74 & 0.74 \\
\hline & 29 & 5 & 0.65 & 0.07 & 0.53 & 0.66 & 0.72 & 0.72 \\
\hline & 30 & 7 & 0.54 & 0.08 & 0.42 & 0.53 & 0.67 & 0.67 \\
\hline & 31 & 5 & 0.56 & 0.08 & 0.49 & 0.52 & 0.66 & 0.66 \\
\hline & 32 & 8 & 0.58 & 0.03 & 0.52 & 0.58 & 0.64 & 0.64 \\
\hline & 33 & 12 & 0.57 & 0.10 & 0.39 & 0.57 & 0.70 & 0.70 \\
\hline & 34 & 8 & 0.59 & 0.10 & 0.43 & 0.58 & 0.77 & 0.77 \\
\hline & 35 & 18 & 0.55 & 0.06 & 0.47 & 0.55 & 0.67 & 0.67 \\
\hline & 36 & 9 & 0.50 & 0.09 & 0.38 & 0.49 & 0.69 & 0.69 \\
\hline & 37 & 7 & 0.52 & 0.04 & 0.43 & 0.53 & 0.56 & 0.56 \\
\hline & 38 & 6 & 0.55 & 0.03 & 0.52 & 0.54 & 0.59 & 0.59 \\
\hline & 39 & 2 & 0.48 & 0.04 & 0.45 & 0.48 & 0.51 & 0.51 \\
\hline
\end{tabular}

Table 3. 5th, 50th, 95th percentile values for Doppler waveform RI of Mean cerebral artery 


\begin{tabular}{|c|c|c|c|c|c|c|c|c|}
\hline & & Dop & r wave & rm RI c & Mean c & ebral arte & & \\
\hline & & $\mathrm{n}$ & Mean & SD & $\begin{array}{l}\text { 5th } \\
\text { centile }\end{array}$ & Median & 95th centile & Maximum \\
\hline$A G$ & 28 & 6 & 0.82 & 0.04 & 0.76 & 0.82 & 0.87 & 0.87 \\
\hline (wk) & 29 & 5 & 0.80 & 0.07 & 0.69 & 0.81 & 0.86 & 0.86 \\
\hline & 30 & 7 & 0.73 & 0.05 & 0.64 & 0.75 & 0.80 & 0.80 \\
\hline & 31 & 5 & 0.72 & 0.13 & 0.49 & 0.77 & 0.82 & 0.82 \\
\hline & 32 & 8 & 0.79 & 0.05 & 0.71 & 0.79 & 0.85 & 0.85 \\
\hline & 33 & 12 & 0.77 & 0.07 & 0.65 & 0.77 & 0.87 & 0.87 \\
\hline & 34 & 8 & 0.77 & 0.06 & 0.68 & 0.79 & 0.84 & 0.84 \\
\hline & 35 & 18 & 0.76 & 0.08 & 0.50 & 0.79 & 0.85 & 0.85 \\
\hline & 36 & 9 & 0.75 & 0.08 & 0.60 & 0.77 & 0.85 & 0.85 \\
\hline & 37 & 7 & 0.74 & 0.05 & 0.64 & 0.73 & 0.82 & 0.82 \\
\hline & 38 & 6 & 0.76 & 0.08 & 0.63 & 0.79 & 0.83 & 0.83 \\
\hline 39 & 2 & 0.79 & 0.05 & 0.75 & 0.79 & 0.82 & 0.82 & \\
\hline
\end{tabular}

Table 4. 5th, 50th, 95th percentile values for Doppler waveform RI of left uterine artery, 


\begin{tabular}{|c|c|c|c|c|c|c|c|c|}
\hline & & \multicolumn{7}{|c|}{ Doppler waveform RI of left uterine artery } \\
\hline & & $\mathrm{n}$ & Mean & SD & 5thcentile & Median & 95thcentile & Maximum \\
\hline \multirow{11}{*}{$\begin{array}{l}\text { AG } \\
(w k)\end{array}$} & 28 & 6 & 0.43 & 0.11 & 0.29 & 0.41 & 0.61 & 0.61 \\
\hline & 29 & 5 & 0.48 & 0.06 & 0.41 & 0.47 & 0.57 & 0.57 \\
\hline & 30 & 7 & 0.46 & 0.11 & 0.36 & 0.44 & 0.69 & 0.69 \\
\hline & 31 & 5 & 0.48 & 0.07 & 0.40 & 0.45 & 0.56 & 0.56 \\
\hline & 32 & 8 & 0.48 & 0.09 & 0.33 & 0.51 & 0.59 & 0.59 \\
\hline & 33 & 12 & 0.46 & 0.08 & 0.32 & 0.47 & 0.57 & 0.57 \\
\hline & 34 & 8 & 045 & 0.06 & 0.37 & 0.43 & 0.54 & 0.54 \\
\hline & 35 & 18 & 0.49 & 0.09 & 0.31 & 0.50 & 0.60 & 0.60 \\
\hline & 36 & 9 & 0.48 & 0.08 & 0.40 & 0.44 & 0.61 & 0.61 \\
\hline & 37 & 7 & 0.52 & 0.10 & 0.38 & 0.49 & 0.65 & 0.65 \\
\hline & 38 & 6 & 0.37 & 0.06 & 0.29 & 0.38 & 0.42 & 0.42 \\
\hline 39 & 2 & 0.45 & 0.00 & 0.45 & 0.45 & 0.45 & 0.45 & \\
\hline
\end{tabular}

Table 5. 5th, 50th, 95th percentile values for Doppler waveform RI of right uterine artery, 


\begin{tabular}{|c|c|c|c|c|c|c|c|c|}
\hline & & \multicolumn{7}{|c|}{ Doppler waveform RI of right uterine artery } \\
\hline & & $\mathrm{n}$ & Mean & SD & 5thcentile & Median & 95thcentile & Maximum \\
\hline \multirow{11}{*}{$\begin{array}{l}A G \\
(w k)\end{array}$} & 28 & 6 & 0.45 & 0.03 & 0.41 & 0.44 & 0.49 & 0.49 \\
\hline & 29 & 5 & 0.49 & 0.02 & 0.46 & 0.50 & 0.51 & 0.51 \\
\hline & 30 & 7 & 0.46 & 0.11 & 0.36 & 0.44 & 0.70 & 0.70 \\
\hline & 31 & 5 & 0.52 & 0.08 & 0.41 & 0.56 & 0.60 & 0.60 \\
\hline & 32 & 8 & 0.49 & 0.05 & 0.42 & 0.49 & 0.55 & 0.55 \\
\hline & 33 & 12 & 0.47 & 0.08 & 0.35 & 0.48 & 0.58 & 0.58 \\
\hline & 34 & 8 & 0.52 & 0.09 & 0.39 & 0.51 & 0.68 & 0.68 \\
\hline & 35 & 18 & 0.50 & 0.07 & 0.36 & 0.51 & 0.62 & 0.62 \\
\hline & 36 & 9 & 0.44 & 0.10 & 0.30 & 0.44 & 0.59 & 0.59 \\
\hline & 37 & 7 & 0.53 & 0.07 & 0.44 & 0.53 & 0.66 & 0.66 \\
\hline & 38 & 6 & 0.46 & 0.05 & 0.40 & 0.45 & 0.53 & 0.53 \\
\hline 39 & 2 & 0.61 & 0.01 & 0.60 & 0.61 & 0.62 & 0.62 & \\
\hline
\end{tabular}

\section{Association between Resistive index and the materno - fetal parameters}

Inverse mild correlation was found between RI UmA values and both GA in week $(r=-0.338, p=0.001)$ and EFW $(-0.445, p=0.00)$ meaning that the resistivity of the umbilical arteries links with GA and EFW; it reduces with the progress of pregnancy.

None of MCA, RUt nor LUt revealed such association with marteno - fetal parameters. All these Pearson correlation coefficients is presented in details in Table 6.

Table 6: Correlation between Resistives index and materno - fetal parameters 


\begin{tabular}{|lllllll|}
\hline Parameters & \multicolumn{7}{l}{ Maternal age } & \multicolumn{2}{l|}{ Gestational age } & EFW & \\
\cline { 2 - 7 } & $\mathrm{r}$ & $\mathrm{p}$ & $\mathrm{r}$ & $\mathrm{p}$ & $\mathrm{r}$ & $\mathrm{P}$ \\
\hline Ombilical artery RI & 0.215 & 0.03 & -0.338 & $\leq 0.001$ & -0.445 & $\leq 0.001$ \\
\hline Mean cerebral artery RI & -0.029 & 0.78 & -0.117 & 0.26 & -0.160 & 0.13 \\
\hline CPR & -0.174 & 0.09 & 0.314 & $\leq 0.001$ & 0.234 & 0.02 \\
\hline Uterine artery RI & & & & & & \\
\hline Right & -0.040 & 0.70 & 0.132 & 0.20 & -0.051 & 0.63 \\
\hline Left & 0.018 & 0.87 & -0.006 & 0.95 & -0.098 & 0.35 \\
\hline
\end{tabular}

\section{Cerebro - placental ratio}

The calculated CPR was positively correlated with fetal characteristics (Table 6). It suppose that the CPR increase with the evolution of pregnancy and may varies at the same GA with the EFW. The mean, 5th and 95th percentiles values of CPR is shown in table 7.

Table 7: 5th, 50th, 95th percentile values for Cerebro - placental ratio values

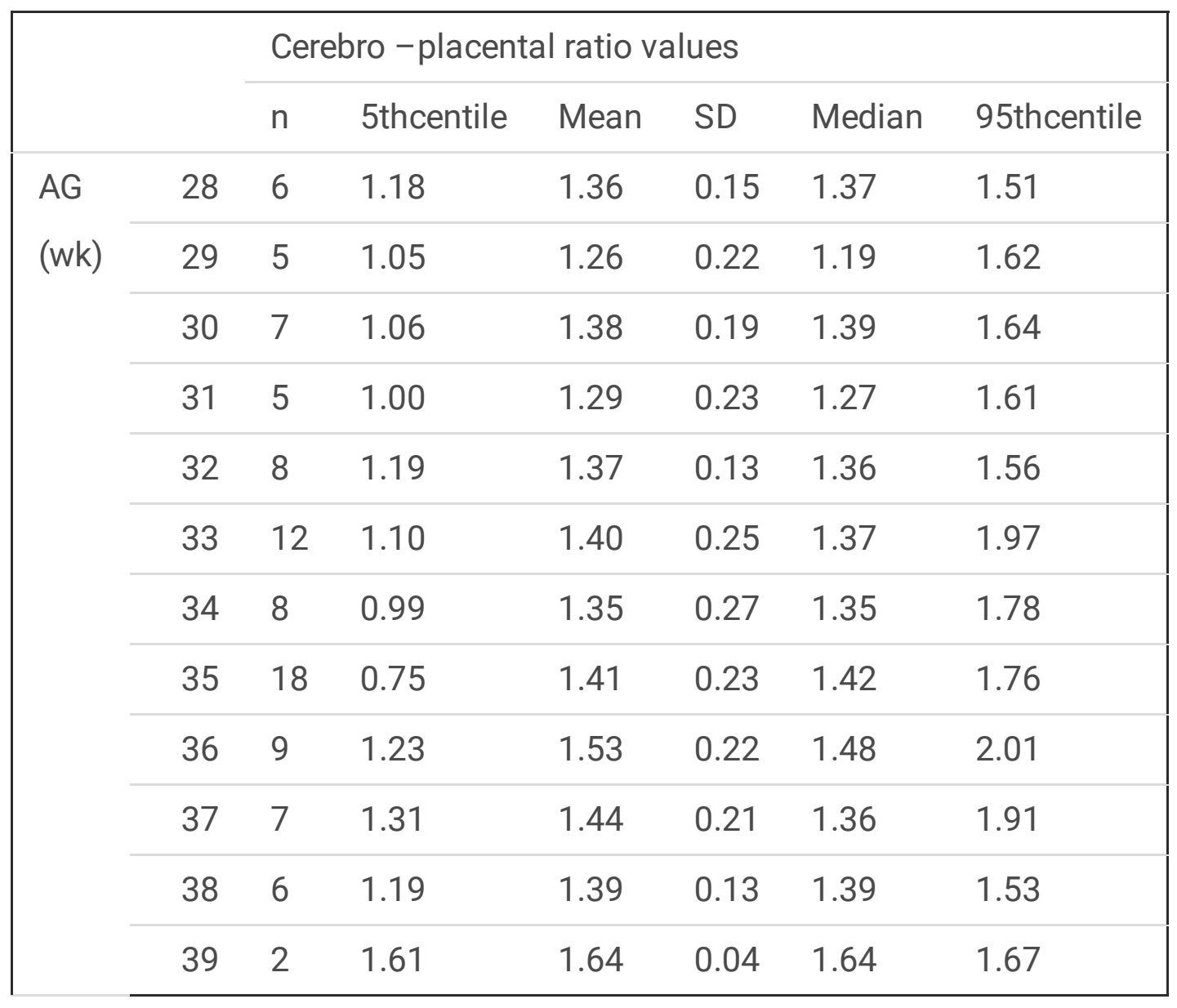




\section{Normogram curves of RI and CPR values (5th to 95th percentiles)}

Regression model fit well by parabolic patterns for all RI values of each target arteries with $R=0.115 ; R=0.028 ; R=0.037$ and $R=0.035$ respectively to UmA, McA, Lut and RUt (Fig 1).

\section{Discussion}

Fetal hemodynamic study is routine in clinical practice since 1977, with the velocymetric analysis of UmA and the MCA and the capacity to diagnose fetal perfusion abnormities $(6,20)$. Therefore, evaluation of the perfusion of intra uterine organs and it correlation with the well - being of the fetus become possible (12), giving a reliable and useful method for pregnancy follow - up. During this study, we determined the Cameroonian reference values of Doppler Resistive index of 4 arteries (UmA, McA, LUt and RUt) on which the fetal hemodynamic evaluation lie on and elaborate the reference curve at 5 th and 95 th percentiles.

This study had shown that these curves have a parabolic pattern and that they have the same shape of others curves found elsewhere in the world $(3,6,14,21-26)$.

\section{Resistive index of umbilical artery.}

The same general findings concerning the RI value of UmA had been made in this study. First we found a decrease of RI UmA value according to the evolution of GA. The fall in RI UmA during the progress of pregnancy reveals a progressive increase of fetal cardiac ejection volume and the decrease of placental vessel resistivity giving to the fetus enought blood supply for its growth. This decrease of the resistivity of UmA is the respond mechanism for a progressive fetal need during growth. The moderate inverse relation found $(r=-0.445, p \leq 0.001)$ between RI UmA and EFW confirm ours assertions. The slightly lower RI values on normogram UmA curves (5th and 95th percentiles) found in this studied population may be partly due to the difference of fetal characteristics in general and in EFW in particular. Kehila et al. in tinusia have demonstrated that the RI UmA values are linearly ( $r=-0.67)$ linked to the fetal growth (here the gain of fetal weight)(27). When we focus on their data like EFW (mean $=2291 \mathrm{~g}$ vs $2337+/-734 \mathrm{~g}$ in ours), RI UmA (mean $=0.63 \mathrm{vs} 0.55$ ) and the extremes ( 0.51 vs 0.51 et 0.77 vs 0.74 ), we remark that ours data seem to follow the same gradient which link the fetal growth but with a deeper decrease of UmA RI. Other Sub Saharan author like Adekanmi et al. in 2016 in Nigeria found the same lower RI tendency in a group of singleton black women with normal pregnancy at the second and the third trimester respectively $0.60+/-0.11$ et $0.53+/-0.11(25)$. At this point, man could question on either the racial specificity or ethnical tendency of this findings that Misra and al found (18) in USA. They found that the magnitude of change in the Umb A RI predicted the EFW in African 
American women. This suggests a careful interpretation of a RI UmA during pregnancy particularly in African women. The relative lack of study in Sub Saharan black African women in general, and in Cameroonian in particular, to the best of our knowledge reveals the interest of the question. Thus, these low normal values tendancy of Umb A RI than those generally describe may justify the utility and the need to elaborated national reference curves of RI during pregnancy. Underlying the fact that for UmA RI, any increase of RI value up to two standard deviation is considered as abnormal and which needs an intervention (23).

\section{Resistive Index of Mean cerebral artery}

Doppler study of the McA have a primordial place in the evaluation of the well- being of the fetus during pregnancy because it directly reveals fetal suffering by evaluating the diastolic flux disturbance in brain. This due to embryologic ranking of blood supply during organogenesis starting first in the cephalic than the caudal portion (28). In this study, we found a cubic pattern of the normogram curves of RI McA and no correlation with GA nor than others fetal characteristics. This contrast with others findings elsewhere concerning only $\mathrm{GA}(3,10,21,24)$. The absence of correlation between RI McA relation with GA found in this study could be explained to fetal characteristics. In fact, our studied population is mostly made up of third trimester pregnant women. During this period, the variation of McA RI does not depend on the fetus himself but depends on the blood flow through placental villi in general, and on the oxygen perfusion in particular $(6,14,24)$. Thus the lack of correlation between McA RI and GA could simply reflect the good staus of placental exchanges and/or the absence of hypoxie or anemia in studied pregnant women that are the direct reflection of the exclusion criterias (Cf materials and methods). It is clearly prove that abnormal oxygen perfusion through placental villi is associated with to a reduction of the brain

vessel resistivity and that Doppler analysis of blood flux in the MCA is a substantial tools in the prediction of the worse neurological outcomes after birth $(6,12,29)$. This is why in clinical situations where UmA RI is normal, only McA RI value less than the 5th percentile is considered abnormal (6). We found 5th percentile McA RI values superior to those generally used $(3,10,21,22)$. These high McA RI values in our studied population support ours previous assertions on the good fetal well - being of pregnant women in this study. Moreover, the absence of correlation between EWF and MCA RI values highlight the absence of a direct link between the fetal growth (pregnancy progress) and the vascular resistance of fetal cerebral vessel generally observed and reported at the third trimester during pregnanct $(1,10,20,29,30)$.

\section{Rigth and Left Uterine arteries Resistive index}

The vascularization of materno - fetal complex is done by uterine arteries. This study 
did not find any correlation between RI values of both LUt and RUt and the materno fetal characteristics. There were no differences between RI values of the LUt and the RUt. Like others normogram curves obtained, RUt and LUt curves had a similar cubic pattern seen elsewere in Africa $(25)$ and in the world $(3,30,31)$ but with the RI values slightly lower in our setting. This could be due to sample size, difference in methodology or may be to some racial factors mentioned earlier.

\section{Cerebro - placental RI ratio}

This ratio is often used to clarify clinical situation in which there is opposite variation of UmA, MCA or UmA RI values are normal or low. Our study revealed that the RCP is not constant through the pregnancy after 28 weeks of GA and that its values were correlated either to fetal characteristics (EFW and GA) or Maternal age (Table 6). Many cut of point are proposed in the literature $(<1 ;<1.05 ;<1.08)$ for fetal prognostic prediction during pregnancy $(32,33)$. This study underline, like elsewhere, interest of analysis CPR values according to GA especially after 34 week $(3,21,34,35)$. Then, the decrease of CPR value under the 5th percentile reflect a fetal blood flow redistribution in favor of brain due to decrease of placental perfusion or hypoxia. This phenomenom often observed in pathological situation during pregnancy had been described as the brain sparing effect phenomenom (36).

\section{Study limitation and perspectives}

This study is the first study in Cameroon on resistive index on low risk singleton pregnant women. It provide to physician a national normogram of RI values of UmA, McA, both LUt and RUt that could help for clinical situation after been validate in general mass population. But for us to generalize our result, we should carefully take in consideration the reduced sample size of our studied population limited by the will of strictly fulfill the selection criterias of subject. We used only one experienced ultrasonologist to avoid inter-observer variation and only one high resolution ultrasonography machine and one trans-abdominal transducer to avoid equipment's variation. As well as, our data had higher reliability based on this fact that all gestational age was established by careful history to identifying only patients with accurate date and confirmation by early ultrasound examination. Furthermore, all newborns were proved to have normal growth and having no structural abnormality. The choice of RI was guided by the aim to adapt the normogram to physician aptitudes and competences in one hand, and to physiological mechanisms of fetal hemodynamic in other hand. 


\section{Conclusion}

In conclusion, we believe this study is the first to establish a national normogram of RI values of UmA, McA, both LUt and Rut in Cameroon. It reveals that there is a downward trend of normal RI values of marterno- fetal arteries seek during pregnancy in Sub Saharan black pregnant women compare to those in literature and thus physician should be careful when they analyze them. This highlight the interest of establishing Sub Saharan black pregnant women normogram and to futher introduce them in the clinical practice in general and in Cameroun in particular.

\section{Abbreviations}

CPR: Cerebo -Placental ratio

EDV: End-systolic velocity

EFW: Estimated fetal weight

GA: Gestational age

IUGR: Intra uterine growth

LUt Left uterine artery

MCA: Middle Cerebral artery

PSV : Pick Systolic velocityS

RI : Resistive index

RUt: Right Uterine artery

S/D : Systolic to Diastolic

SD: Standard deviation

\section{Declarations}

- Ethics approval and consent to participate

The study protocol was approved by the Institutional Review Board at the faculty of Medicine and Biomedical Sciences of University of Yaoundé 1 (N431/UY1/FMSB/VDRC/CSD du 24 mai 2017), and each participant in the study submitted a signed and approved informed consent form.

\section{- Consent of publication :}

Not applicable.

- Availability of data and materials 
The datasets used and/or analysed during the current study are available from the corresponding author on reasonable request.

\section{- Competing interests}

The authors report no conflicts of interest. The authors alone are responsible for the content and writing of the paper.

\section{- Funding}

No particular funding was rise by authors for this study.

\section{- Authors' contributions}

BM: Conception, design of the work, interpretation of data and substantively revised.

UT: Design of the work, the acquisition, the analysis, the interpretation of data, drafted the work and substantively revised it.

CJ: Conception, design of the work and the acquisition.

JRM: Conception, design of the work and the acquisition,

PF: Conception, design of the work and substantively revised.

All authors have read and approved the manuscript.

\section{- Acknowledgements}

Not applicable.

\section{References}

1. Dubiel M, Breborowicz GH, Marsal K, Gudmundsson S. Fetal adrenal and middle cerebral artery Doppler velocimetry in high-risk pregnancy: Fetal adrenal artery velocimetry. Ultrasound Obstet Gynecol. 1 oct 2000;16(5):414-8.

2. Capmas P, Senat M-V, Goffinet F. Doppler en obstétrique. EMC - Obstétrique. 2007 Jan; 2(4):1-41.

3. Kurmanavicius J, Florio I, Wisser J, Hebisch G, Zimmermann R, Müller R, et al. Reference resistance indices of the umbilical, fetal middle cerebral and uterine arteries at 24-42 weeks of gestation: Resistance indices. Ultrasound Obstet Gynecol. 1 août 1997;10(2):112-20.

4. FitzGerald DE, Drumm JE. Non-invasive measurement of human fetal circulation using ultrasound: a new method. BMJ. 3 déc 1977;2(6100):1450-1. 
5. Bower S, Schuchter K, Campbell S. Doppler ultrasound screening as part of routine antenatal scanning: prediction of pre-eclampsia and intrauterine growth retardation. BJOG Int J Obstet Gynaecol. nov 1993;100(11):989-94.

6. Seravalli V, Baschat AA. A Uniform Management Approach to Optimize Outcome in Fetal Growth Restriction. Obstet Gynecol Clin North Am. juin 2015;42(2):275-88.

7. Bewley S, Cooper D, Campbell S. Doppler investigation of uteroplacental blood flow resistance in the second trimester: a screening study for pre-eclampsia and intrauterine growth retardation. BJOG Int J Obstet Gynaecol. sept 1991;98(9):871-9.

8. Hernandez-Andrade E, Scheier M, Dezerega V, Carmo A, Nicolaides KH. Fetal middle cerebral artery peak systolic velocity in the investigation of non-immune hydrops: Doppler in non-immune hydrops. Ultrasound Obstet Gynecol. mai 2004;23(5):442-5.

9. Kassanos D, Siristatidis C, Vitoratos N, Salamalekis E, Creatsas G. The clinical significance of Doppler findings in fetal middle cerebral artery during labor. Eur J Obstet Gynecol Reprod Biol. juill 2003;109(1):45-50.

10. Bahlmann F, Reinhard I, Krummenauer F, Neubert S, Macchiella D, Wellek S. Blood flow velocity waveforms of the fetal middle cerebral artery in a normal population: reference values from 18 weeks to 42 weeks of gestation. J Perinat Med [Internet]. 3 janv 2002 [cité 26 août 2020];30(6). Disponible sur: https://www.degruyter.com/view/j/jpme.2002.30.issue6/jpm.2002.077/.jpm.2002.077.xml

11. Mandruzzato G. Obstetrical Doppler: the evidence today. J Perinat Med [Internet]. 1 janv 2015 [cité 26 août 2020];43(2). Disponible sur: https://www.degruyter.com/view/j/jpme.2015.43.issue-2/jpm2014-0307/jpm-2014-0307.xml

12. Chanprapaph $\mathrm{P}$, Tongsong $\mathrm{T}$, Siriaree $\mathrm{S}$. Validity of antenatal diagnosis of intrauterine growth restriction by umbilical Doppler waveform index. J Med Assoc Thail Chotmaihet Thangphaet. 2004;87:492-6.

13. Acharya G, Wilsgaard T, Berntsen GKR, Maltau JM, Kiserud T. Reference ranges for serial measurements of umbilical artery Doppler indices in the second half of pregnancy. Am J Obstet Gynecol. mars 2005;192(3):937-44.

14. Gómez O, Figueras F, Fernández S, Bennasar M, Martínez JM, Puerto B, et al. Reference ranges for uterine artery mean pulsatility index at 11-41 weeks of gestation. Ultrasound Obstet Gynecol. août 2008;32(2):128-32.

15. Arbeille P, Carles G, Bousquet F, Body G, Lansac J. Fetal cerebral and umbilical artery blood flow changes during pregnancy complicated by malaria. J Ultrasound Med. avr 1998;17(4):223-9.

16. ISUOG Practice Guidelines: use of Doppler ultrasonography in obstetrics: ISUOG Guidelines. Ultrasound Obstet Gynecol. févr 2013;41(2):233-9.

17. Massoud M, Duyme M, Fontanges M, Combourieu D. Courbe d'estimation de poids fœtal 2014 par le Collège français d'échographie fœtale (CFEF). J Gynécologie Obstétrique Biol Reprod. janv 2016;45(1):80-5. 
18. Misra VK, Hobel CJ, Sing CF. Ethnic heterogeneity in the longitudinal effects of placental vascular blood flow on birthweight. Am J Obstet Gynecol. janv 2008;198(1):72.e1-72.e8.

19. Hadlock FP, Harrist RB, Sharman RS, Deter RL, Park SK. Estimation of fetal weight with the use of head, body, and femur measurements-A prospective study. Am J Obstet Gynecol. févr 1985;151(3):333-7.

20. Kalache KD, Dückelmann AM. Doppler in Obstetrics: Beyond the Umbilical Artery. Clin Obstet Gynecol. mars 2012;55(1):288-95.

21. Baschat AA, Gembruch U. The cerebroplacental Doppler ratio revisited: Cerebroplacental Doppler ratio. Ultrasound Obstet Gynecol. févr 2003;21(2):124-7.

22. Mari G, Deter RL. Middle cerebral artery flow velocity waveforms in normal and small-for-gestationalage fetuses. Am J Obstet Gynecol. avr 1992;166(4):1262-70.

23. Palacio M, Figueras F, Zamora L, Jiménez JM, Puerto B, Coll O, et al. Reference ranges for umbilical and middle cerebral artery pulsatility index and cerebroplacental ratio in prolonged pregnancies: Fetal Doppler velocimetry reference ranges. Ultrasound Obstet Gynecol. nov 2004;24(6):647-53.

24. Tarzamni MK, Nezami N, Sobhani N, Eshraghi N, Tarzamni M, Talebi Y. Nomograms of Iranian fetal middle cerebral artery Doppler waveforms and uniformity of their pattern with other populations' nomograms. BMC Pregnancy Childbirth. déc 2008;8(1):50.

25. Adekanmi A, Roberts A, Adeyinka A, Umeh E, Anor F, Odo J, et al. Normal second and third trimester uterine and umbilical doppler indices among healthy singleton gestation Nigerian women. West Afr J Radiol. 2017;24(1):1.

26. Chang C-P, Wang H-I, Wang P-H, Yang M-J, Chang C-M, Juang C-M, et al. Umbilical artery Doppler velocimetry in normal pregnancies from $11+0$ to $13+6$ gestational weeks: A Taiwanese study. Taiwan J Obstet Gynecol. juin 2014;53(2):193-6.

27. Kehila M, Hmid B, Karoui A, Abouda S, Badis M. Corrélation entre l'index de résistance ombilicale et le gain pondéral foetal Etude prospective à propos de 30 cas Correlation between umbilical resistance index and fetal weight gain Prospective study about 30 cases. Rev Tunsienne Gynécologie Obstétrique Fertil. 1 sept 2015;2.

28. A. Kurjak, Kupesic S. Blood Flow Studies in Early Pregnancy. In: Kurjak, AKS, Ed, Color Doppler in Obstetrics. ArtStudio Azinovic-Medison. Zagreb-Seoul; 1999. p. 87-108. (Gynecology and Infertility).

29. Fardiazar Z, Atashkhouei S, Yosefzad Y, Goldust M, Torab R. Comparison of fetal middle cerebral arteries, umbilical and uterin artery color Doppler ultrasound with blood gas analysis in pregnancy complicated by IUGR. Iran J Reprod Med. janv 2013;11(1):47-51.

30. Cruz-Martinez R, Savchev S, Cruz-Lemini M, Mendez A, Gratacos E, Figueras F. Clinical utility of thirdtrimester uterine artery Doppler in the prediction of brain hemodynamic deterioration and adverse perinatal outcome in small-for-gestational-age fetuses. Ultrasound Obstet Gynecol. mars 2015;45(3):273-8.

31. Lakhkar B, Ahamed S. Doppler velocimetry of uterine and umbilical arteries during pregnancy. Vol. 9, Indian Journal of Radiology and Imaging. Wolters Kluwer Medknow Publications; 1999. p. 119-25. 
32. Odibo AO, Riddick C, Pare E, Stamilio DM, Macones GA. Cerebroplacental Doppler Ratio and Adverse Perinatal Outcomes in Intrauterine Growth Restriction: Evaluating the Impact of Using Gestational Age-Specific Reference Values. J Ultrasound Med. sept 2005;24(9):1223-8.

33. DeVore GR. The importance of the cerebroplacental ratio in the evaluation of fetal well-being in SGA and AGA fetuses. Am J Obstet Gynecol. juill 2015;213(1):5-15.

34. Bahado-Singh RO, Kovanci E, Jeffres A, Oz U, Deren O, Copel J, et al. The Doppler cerebroplacental ratio and perinatal outcome in intrauterine growth restriction. Am J Obstet Gynecol. mars 1999;180(3):750-6.

35. Ebbing C, Rasmussen S, Kiserud T. Middle cerebral artery blood flow velocities and pulsatility index and the cerebroplacental pulsatility ratio: longitudinal reference ranges and terms for serial measurements. Ultrasound Obstet Gynecol. sept 2007;30(3):287-96.

36. Scherjon SA, Smolders-DeHaas H, Kok JH, Zondervan HA. The "brain-sparing" effect: Antenatal cerebral Doppler findings in relation to neurologic outcome in very preterm infants. Am J Obstet Gynecol. juill 1993;169(1):169-75.

\section{Figures}
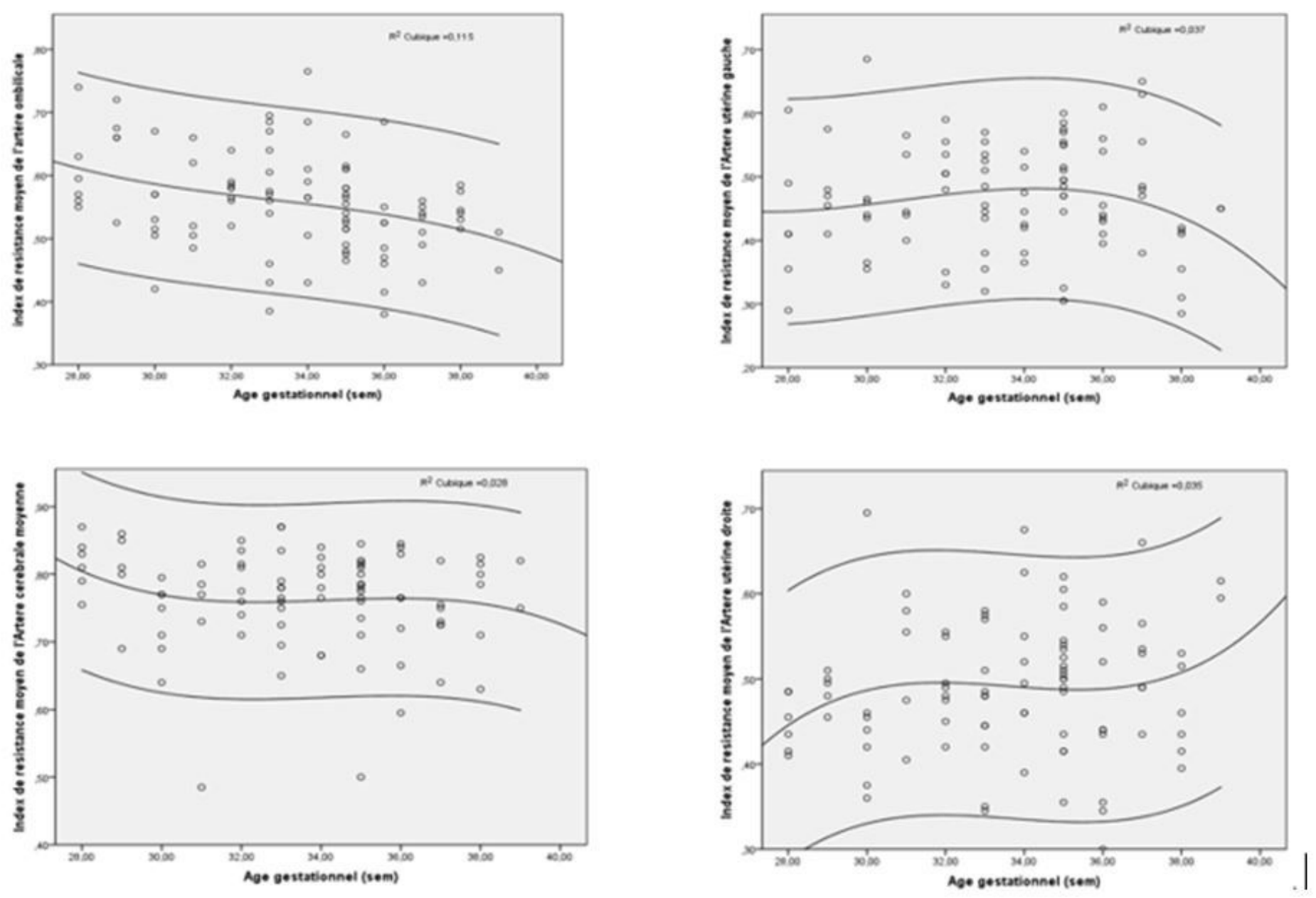


\section{Figure 1}

Individual measurements and calculated reference ranges for the resistive index (RI) in the UmA, the MCA, the LUt and RUt. 